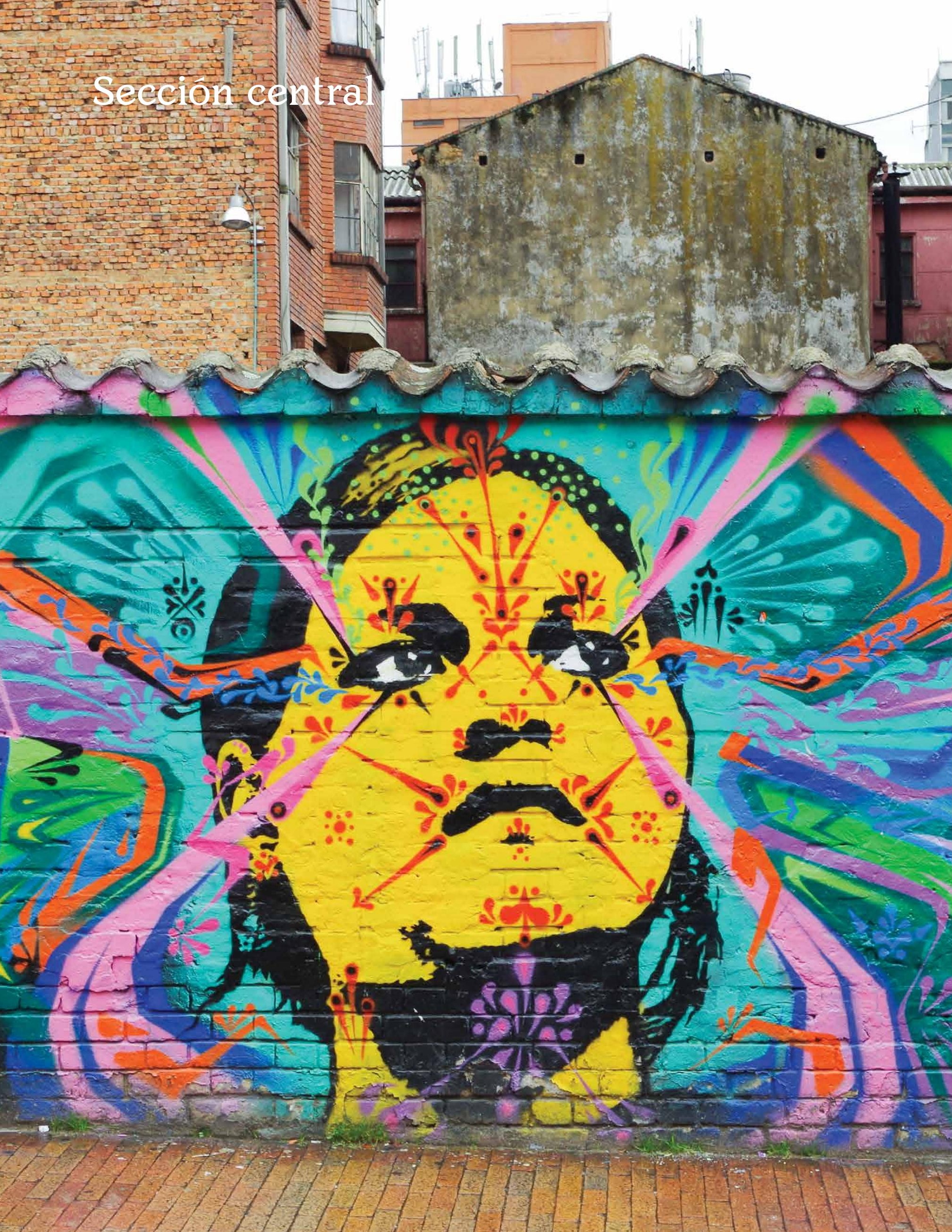




\section{De la gestión y la política cultural. Conversación con Clarisa Ruiz Correal}

\section{Artículo de reflexión}

Recibido: 25 de abril de 2007

Aprobado: 18 de mayo de 2017

PhD. Marta Bustos Gómez

Universidad Distrital Francisco José de Caldas

mlbustosg@udistrital.edu.co

Clarisa Ruiz Correal

Fundación Liebre Lunar para el arte y la cultura clarisaruizc@gmail.com

Cómo citar este artículo: Bustos Gómez, Marta (2017). De la gestión y la política cultural. Conversación con Clarisa Ruiz Correal. Estudios Artísticos: revista de investigación creadora, 3 (3) pp. 87-97. DOI: https://doi.org/10.1448/ear. v3i3.12530

Fotografía de Josh Levinger, tomada de Flickr https://www.flickr.com/photos/ilevinger/14300455289/

\section{Resumen}

Esta entrevista con Clarisa Ruiz Correal, hace parte de un proyecto de mayor envergadura que busca indagar por las prácticas de la gestión cultural en Colombia y en la ciudad de Bogotá principalmente a partir de la voz de sus protagonistas. En un tono autobiográfico, se pretende explorar de qué manera han configurado sus acciones, cuál ha sido su posición frente a las esferas del poder y a las instituciones o dependencias que han dirigido, cómo han asumido o sido parte de los elementos declarativos de la retórica institucional y cuál ha sido su particular visión para concretar tanto el horizonte de sentido como el desarrollo organizacional de su gestión en el campo cultural.

\section{Palabras clave}

Política cultural, autobiografía, entrevista, gestión cultural.

\section{Of Cultural Management and Policy. A Conversation with Clarisa Ruiz Correal}

\footnotetext{
Abstract

This interview with Clarisa Ruiz Correal, is part of a larger project that seeks to research the practices of cultural management in Colombia and the city of Bogotá, mainly from the voice of its protagonists. In an autobiographical tone, the aim is to explore how they have configured their actions, what their position has been vis-a-vis the spheres of power and the institutions or agencies they have led, how they have assumed or been part of the declarative elements of institutional rhetoric. Finally, what has been their particular vision to realize both the horizon of meaning and the
} 
organizational development of their management in the cultural field.

\section{Keywords}

Cultural policy, autobiography, interview, cultural management.

\section{De la gestion et de la politique culturelle. Une conversation avec clarisa ruiz correal}

\section{Résumé}

Cet entretien avec Clarisa Ruiz Correal fait partie d'un projet plus vaste qui cherche à étudier les pratiques de gestion culturelle en Colombie et à la ville de Bogotá, principalement à partir de la voix de ses protagonistes. Dans un ton autobiographique, l'objectif est d'explorer comment ils ont configuré leurs actions, quelle est leur position vis-à-vis des sphères de pouvoir et des institutions ou agences qu'ils ont menées, comment ils ont assumé ou fait partie des éléments déclaratives de la rhétorique institutionnelle, et quelle a été sa vision particulière pour réaliser à la fois Ishorizon du sens et le développement organisationnel de sa gestion dans le domaine culturel.

\section{Mots clés}

Politique culturelle, autobiographie, entretien, gestion culturelle.

\section{Da gestão e da política cultural. Conversa Clarisa Ruiz Correal}

\section{Resumo}

Esta entrevista com Clarisa Ruiz Correal faz parte de um projeto de maior envergadura que busca indagar as práticas da gestão cultural na Colômbia e na cidade de Bogotá, principalmente, a partir da voz de seus protagonistas. Em um tom autobiográfico, se pretende explorar de que maneira tem configurado suas ações, qual tem sido sua posição frente às esferas do poder e às instituições ou agências que tem dirigido, como tem assumido ou feito parte dos elementos definidores da retórica institucional e qual tem sido sua particular visão para consolidar tanto o horizonte de sentido quanto o desenvolvimento organizacional de sua gestão no campo cultural.

\section{Palavras-chave}

Política cultural, autobiografia, entrevista, gestão cultural.

\section{Gestionmanda y Política Culturalmanda. Parlo Clarisa Ruiz Correal}

\section{Maillallachiska}

Kai entrevistak Clarisa Ruiz Correal, kanme sug atun proyecto y maskakume practicakuna gestión culturalua Colombiape y mas Bogota Ciudadpe voz protagonista kunapa. Autobiograficoua, mascarikumi. Imasami ka configurado paikunapa accionkuna. Imasatak ka paipa poder esfera poderkunape elementokuna declarativos retorica institucional imasatak ka paipa kauni particular concretangapa horizontepe y desarrollo institucionalpe paipa gestión campo culturalpe.

\section{Rimangapa Ministidukuna}

Política cultural, autobiografía, entrevista, gestión cultural.

Mientras realizaba mi tesis de doctorado sobre políticas culturales en Bogotá, me encontré con archivos de prensa que registraban los cambios de directivos de alguna de las instituciones culturales del país. En particular me llamo la atención una nota del año de 1986 de la Revista Consigna, titulada "Finalmente... Un hombre en Colcultura" a raíz de la salida de Amparo Carvajal y de la designación de Carlos Valencia como director del Instituto Colombiano de Cultura, Colcultura, entidad creada durante el gobierno liberal de Carlos Lleras Restrepo como parte del Plan de las Américas y máximo ente de dirección cultural dentro del Estado colombiano, entre 1969 y 1991. El artículo, además de señalar el exiguo presupuesto de la entidad y la poca claridad sobre sus funciones, subrayaba que había un avance interesante para la rectoría cultural de esta institución, pues según el autor "cambiamos de sexo".

Esta afirmación me llevo a revisar la lista de directores de Colcultura y allí encontré que al poeta Jorge Rojas, como primer director le siguieron un grupo de mujeres con perfiles discutidos en mayor o menor medida en su momento y cuyo trabajo ha 
sido objeto de apasionados debates, profundos amores y vehementes odios. Gloria Zea de Uribe, durante los gobiernos de Alfonso López Michelsen (1974-1978) y Julio César Turbay Ayala (1978-1982), Aura Lucía Mera y Amparo Sinisterra de Carvajal, en la administración de Belisario Betancur (1982-1986), Liliana Bonilla (1990) con Virgilio Barco e Isadora de Norden (1996), en el gobierno de Ernesto Samper. Dirigieron con aciertos y desaciertos, los destinos de la entidad, que, adscrita al Ministerio de Educación, se encargó por cerca de veinte años de las políticas culturales en el país.

Junto a ellas hay un grupo de mujeres que por diversas circunstancias, en diferentes ámbitos y más allá de sus diferencias conceptuales y generacionales han ejercido el poder que denota asumir la dirección de una entidad estatal o alguna de sus dependencias en un país donde la arquitectura institucional pública ha sido precaria y donde el ámbito de la gestión cultural aunque sea una minoría en términos de la administración gubernamental motiva intensas pasiones. El uso de la entrevista, o mejor la conversación, como metodología que requiere la presencia de las emociones y el concurso no solamente de la inteligencia racional sino de las afecciones, percepciones, de la intuición y la imaginación, es parte de un ejercicio que busca expandir los espacios de emergencia del saber, las ideas de sujeto cognoscente y reivindicar el conocimiento corporizado, localizado y subjetivizado que este grupo de mujeres poseen.

Marta Bustos Gómez: ¿Cómo se define?

Clarisa Ruiz Correal: Como una gestora cultural y escritora para niños. Esta es una respuesta de los tiempos recientes, cuando la gestión cultural aparece más definida y reconocida. También, luego de hacer un balance de mi propio recorrido. Por los años 90's me afirmaba como profesional de la filosofía y a comienzos del siglo, como promotora de las artes. Me interesaba distinguir el trabajo con el arte de la gestión cultural, esto porque durante muchos años solo trabajé para el campo artístico en específico y quería subrayarlo. Había en esto un deseo de afirmar el arte (en una concepción amplia, contemporánea) y de distinguirlo de las posiciones "culturalistas" que, a mi modo de ver, diluían la especificidad de la creación. He tenido dudas sobre mi identidad profesional. Ellas provienen de mi diversidad de intereses (las prácticas artísticas, la filosofía, la antropología) y de la inexistencia por muchos años de unas carreras profesionales interdisciplinares. Pienso que eso está apenas comenzando a cambiar. Podría ser también que haya habido una artista que no logró concretarse pero que vive su base en la filosofía y la gestión cultural como experiencias artísticas creadoras.

MBG: El término gestión aparece en los años 80's en las instituciones gubernamentales pero desde mucho antes se hacía una labor de "gestión" en el campo cultural. De hecho su padre, Jorge Eliécer Ruíz, fue un intelectual que se desempeñó de manera destacada en este ámbito. Desde su experiencia nos podría decir cuáles han sido las transformaciones más significativas en el ámbito de la gestión cultural gubernamental.

CRC: Es muy interesante hacer la genealogía de la objetivación de lo cultural como un ámbito específico de la política pública en Colombia. Por una parte, en los 60's empieza a aparecer en el país lo que se denominaba la "extensión cultural" en Universidades y en las administraciones de Bogotá, por ejemplo. Abogados, hombres, eran la mayor fuente de intelectuales que dividian su vida entre el oficio o la burocracia y la práctica de las artes, la literatura principalmente. Jorge Rojas, Pedro Gómez Valderrama. De ellos fue mi padre. En los círculos de intelectuales, aparecían algunos que se quedaban en una zona intermedia, no desarrollaban una obra, tampoco llevaban una doble vida profesional, ellos empezaron a trabajar en asuntos relacionados con la educación y la "extensión" cultural. Por otra parte, estaba la relación educación y cultura, hoy prácticamente inexistente en Colombia en el ámbito institucional. Por la dificultad que se tuvo en integrar la educación en artes, surgieron las escuelas y procesos formativos en artes que empezó a asumir aquella extensión cultural. De estas vertientes empieza a surgir el ámbito cultural en Colombia y personas que se dedicaron a esa zona intermedia entre las artes y las ciencias sociales y la administración pública.

Posteriormente, Jorge Eliécer Ruíz y el grupo de personas que trabajaron en Colcultura con Gloria Zea, una profesional de la filosofía y miembro de las elites, conformaron un grupo muy compacto, entusiasta, humanista. Estaba Juan Gustavo Cobo, Santiago Mutis y, de manera más tangencial, Hernando Valencia Goelkel. Intelectuales, en su 
mayoría hombres, muy cercanos a las artes, pero también personas que pensaron y desarrollaron programas e instituciones en el patrimonio, en las ciencias sociales, la antropología, las lenguas, la ciencia y la historia, en resumen, para decirlo en palabras que usamos mucho hoy, intelectuales que tenían una concepción expandida de lo cultural. Se redactaron entonces los primeros textos sobre políticas culturales, bajo la egida de la UNESCO. Este referente internacional y el modelo francés, dieron una base de organización a la política cultural estable, que le permitió también una relativa autonomía de la politiquería. Desde el centro, se desplegó una amplia y diversificada actividad en el país, anunciando y enunciando principios y relaciones de un tejido cultural complejo, que alcanzó a concretarse en instituciones que luego languidecieron o murieron en los neoliberales años 90's. La Biblioteca Básica Colombiana de Colcultura que ya no comportaba solamente la literatura, Los Salones Regionales, la Segunda Expedición Botánica, el Centro de Estudios Lingüísticos de la Universidad de los Andes. La ópera que itineraba por más de 10 ciudades. Prevalecía el paradigma de la democratización de la cultura. Digamos que esta fue la época de la "ilustración" (idel despotismo ilustrado?), con todas las cargas que ello conlleva.

En los años 90's, Colcultura siguió "irradiando" desde el centro, con un fuerte acento en las artes, apegado al canon occidental. La Constitución del 91 dio gran relevancia al tema cultural, fundamento de la nacionalidad. Basada en el espíritu de los Derechos Humanos, los redactores de la nueva Constitución abrieron muchas posibilidades al campo cultural también entendido como un espacio más allá de las artes (con lo que he tenido siempre problemas, debería ser además de). Una Constitución que conjugo la paradoja de la diversidad y la universalidad, la nacional y la de los territorios. Muchos no pudieron conjugar estas fronteras y hoy en día gran parte de ese espíritu no ha calado en las esferas de los dirigentes políticos de este país.

Sobreviene la llegada de Ramiro Osorio, uno de los pocos artistas en los cargos gubernamentales de la cultura, con los poetas Darío Jaramillo y Jorge Rojas. Esto también para estudiar los perfiles de la dirigencia cultural. Ramiro tiene la ambición del tamaño del imperio mexicano, país que fue su segunda patria. Recorrieron el país, montaron Ios Talleres Nacionales itinerantes, desarrollaron infraestructura, trataron de salir de las fronteras del altiplano y atender las regiones más allá de sus capitales. Eran tiempos de descentralización, también en que morían las Escuelas de Artes como la EPA de Medellín, la de Ocaña, Sincelejo. Empezaba la época de la participación. Y Ramiro montó la Ley General de Cultura con un equipo que conocía la política cultural por la práctica. En realidad, llevaban el arte y la cultura en la sangre: Álvaro Restrepo, Adelaida Nieto, Felipe Aljure. Siempre habrá que mencionar a Miguel Durán de manera especial, él, abogado-teatrero, anduvo el país apoyando las causas culturales en las regiones. La Ley buscó dar cuenta del país a través del Sistema Nacional de Cultura, ordenando la participación y encajonándola. Dejaron por fuera la institucionalidad municipal, la obligación de contar con planes municipales anuales, lo que si se hizo con el Sistema Ambiental. Bajo la sombrilla de los Derechos Humanos y la nueva Constitución, el sector cultural se articuló con una mano a los objetivos globales de participación, descentralización, diversidad; con la otra mano, al desarrollo de las industrias culturales, la cultura como buen uso del tiempo libre y "recurso", la estandarización y la reducción del estado como cabeza de lo público...

Bogotá ha sido buena alumna de la Ley. Mientras que el Ministerio fue usado y abusado al final del milenio. Fue el Ministerio de la Paz, de los diálogos de nación de 6 ministros en menos de 6 años. Mención especial me parece que merece la elección de la cacica Consuelo Araujo y las polémicas que propició con su defensa del folclor y ataques a los cuellos blancos de la cultura. Años de despliegue en el territorio y también de mucha retórica.

El nuevo siglo nos despertó con un Plan Decenal contundente, riguroso, que fue apropiado por numerosos gestores culturales en todo el país y construyó un lenguaje común. Una carta constitucional para la cultura contemporánea, ambiciosa. Habrá que reconocer a sus últimos redactores. Pero también nos sorprendió matando las agrupaciones nacionales que por medio siglo se habían logrado sostener. Queríamos abrirnos a nuestras raíces y diversidad pero no necesariamente, liquidando un sindicato de dientes de leche de una agrupación cuyo costo no subía de los 4 mil 
millones de pesos. Esa era otra paradoja con la que debíamos lidiar: trabajar con formatos modernos para los tiempos postmodernos. "¿Era posible transformar mentalidades, representaciones desde instituciones vehículo del espíritu colonial?" Esa pregunta me la hacía Marina Lamus Obregón cuando fui directora del Colón en los primeros años del milenio. Se focalizó "el reguero" de objetivos de la cultura y se priorizó la música para la convivencia y la lectura. La recurrencia en cultura no era ni bien conocida, ni bien expresada por funcionarios plenos de emotividad y compromiso, pero sin argumentos técnicos ante los burócratas del Departamento Nacional de Planeación, DNP. Me fui del Colón, dejando la zona de confort que ello me representaba, porque la otra candidata a la Dirección de Artes era una economista que, como la Ministra, había llegado al sector por sus carreras político-administrativas. Pensé que debía haber algo de caos y entrega. Con la Ministra Araujo se ordenaron las cosas, se pudo tener un poco más de visión de largo plazo, sin embargo, no se arriesgó a ir más allá. El Ministerio no logró evaluar políticas con el DNP, no fue realmente tomado en cuenta en los grupos intersectoriales que combatían la pobreza, a pesar de estar en el gabinete.

Cierra el decenio la Ministra afrodescendiente Paula Marcela Moreno, con lo cual se pasa de las cuotas regionales a las cuotas étnicas. Muy interesante fue su administración. Las políticas de afirmación de la diversidad se trabajaron, en muchos casos, de manera voluntariosa, enfrentando resistencias tanto de la Presidencia, como del pensamiento y conocimientos que subyacían y subyacen hoy en día a planes y programas. Reconozco principalmente el caso de la "reventada" política musical. Una gestión cultural muy interesante: desplegó internacionalmente, se comprometió con la sistematización de las políticas, buscó Leyes y normas, algunas criticadas por retóricas, pero esto no es el caso aquí. Paralelamente Bogotá y Medellín avanzaban con la enunciación de políticas y planes. Había poco diálogo a pesar de las reuniones de Secretarios. Dos reuniones anuales no lograban generar sinergias. Una década en que madura la institucionalidad central, que se cuenta con una capa de gestores culturales de alguna trayectoria, formados en la práctica del Estado y con asesores desde la Academia, más especializados. Avanzó el reconocimiento y la afirmación de la diversidad, la participación lucha y tiene espacios de decisión en el Cine. Una década en que la institucionalidad sigue siendo como hermano menor del establecimiento, para bien y para mal.

En esta segunda década del milenio me parece que ha decaído la reflexión sobre las políticas. La formación en gestión cultural venía avanzando con fuerza en Medellín, no así en Bogotá. Actualmente me parece que existe gran interés, pero las instituciones no logran tener una posición fuerte respecto de su responsabilidad en este frente. La crisis de la participación normada es patente. La estabilidad de la Ministra, que va para 8 años, se torna tan problemático como la inestable rotación. Esto por cuanto hay poco o ningún interés por el diálogo y debate sobre las políticas culturales por parte del Ministerio. Se puede defender la voluntad de la Ministra de no caer en ideologías direccionistas de la actividad cultural, pero no hay nunca purismo en el Estado. La Cultura oficial o la política cultural del estado podrían definir sus posiciones, sin por ello convertirse en un instrumento al servicio de una u otra ideología. Eso fue lo que intentamos hacer en Bogotá. El Ministerio ha pretendido no meterse en política, ideologías, retóricas... una pretensión a mi manera de ver. Sin duda, es correcto no prestarse a sainetes como los del "Ministerio de la Paz", pero no apropiarse de una posición o un debate, derroteros, orientaciones, frente a los acuerdos y el postconflicto, me parece que deja un vacío, que tal vez, de manera muy astuta los radicalismos están asumiendo. Sin duda, las batallas de este siglo están surgiendo en el campo cultural.

En esta década se profundizó y visibilizó el trabajo cultural comunitario en el país que ya venía surgiendo con fuerza como respuesta al conflicto armado. Las organizaciones se multiplican y tienen ya años de experiencia. Así los principios de proximidad, del "bottom-up", tienen también sus prácticas en Colombia. La propuesta de ir más allá de la diversidad para promover la interculturalidad, es totalmente pertinente en Colombia, un país culturalmente muy deshilvanado por la dificultad del encuentro, los intercambios, la circulación de sus artistas, gestores, cultores. Podría decir que poco se ha desarrollado la dimensión cultural de la política cultural. Seguimos muy apegados a las artes y el patrimonio que, por su parte, de todas formas 
están muy desprotegidos. Pienso que los 20 años que se cumplen en agosto de 2017 de la Ley de Cultura, deberían ser un pretexto para movilizar la reflexión sobre esas características de la política y la institucionalidad cultural en Colombia y para que se señalen nuevos derroteros.

\section{MBG: ¿Cómo ingresa al mundo de la gestión} cultural?

CRC: Regresé al país luego de terminar mi pregrado en Francia y me ofrecieron trabajar en la Galería Santa Fe del Instituto Distrital de Cultura. Tenía otra alternativa que era ingresar a la docencia en la Universidad de los Andes. Después de mucho dudar, me decidí optar por la Galería, eso fue en 1983. Hicimos exposiciones muy hermosas, temáticas, más culturales que artísticas, si se quiere, novedosas para la época: de diseño industrial, de oficios, relacionando arte e industria. Me ufanaba de que el Planetario y su Galería tenían mucho público y un público popular, que el MAMBO no tenía y que la Luis Ángel, lo tenía, pero "amarrado" a la Biblioteca. Sin duda en esas posibilidades laborales que se me abrieron jugaba un rol determinante mi contexto familiar, mi contexto era el de unos intelectuales y artistas muy abiertos, muy activos. Luego, la generación que los siguió, es casi toda de artistas. Yo me quede en la zona intermedia, a pesar de seguir intentando poesía.

En el Festival Iberoamericano de Teatro de Bogotá, FITB, me multipliqué y no hay oficio por el que no haya pasado. Hice contratos, llevaba las sábanas de logística, la publicidad con Ligia Henao, hice traducción, diseñé los espacios de formación y, lo más delicado, fui curadora de Festival y de la Casa del Teatro. Me fui del teatro y del Festival en pos de profundizar en la educación artística, a mi manera de ver la posibilidad de cerrar la brecha entre esas grandes figuras de las artes y nuestros propios artistas. La posibilidad también de un arte que no fuera de talentos excepcionales sino de bases amplias, de todos.

Luego vinieron otros trabajos en la cultura en su mayoría en lo público. Siempre pienso que he sido sostenida en este camino por mi tradición y porque tengo una pasión. No creo ser una gestora formal, internamente soy una artista apasionada. Esto me acompaña aun en el mundo de la planeación, las normas y las contralorías de la función pública.
Después pasé del sector privado al público porque quería trabajar por la educación artística y me ofrecieron la dirección de la Escuela de Artes de Bogotá, ASAB. Esa fue una muy buena decisión en mi vida. De ahí seguí acercándome a lo público.

MBG: ¿Cuáles han sido sus maestros en el campo de la gestión cultural?

CRC: No puedo pensar en una o algunas personas en particular. Se me viene a la cabeza Francia y su política e institucionalidad cultural. No sólo porque allá trabaié en mis primeros años profesionales sino porque estudié, y realicé dos pasantías en el Ministerio de Cultura francés. En la última pasantía estuve en el mismo Ministerio, pero pedí visitar "proyectos sociales" y logré conocer otra cara de la política cultural francesa, mucho más cercana al ciudadano corriente.

De Sylvia Moscovitz, Alejandro González y Ma Zheng Hong, aprendí que el arte es un ejercicio diario, que puede estar en las mínimas acciones. $Y$ aprendí la fuente de energía que resulta ser la producción artística. Con Fanny Mickey y con Ramiro en el FITB, no aprendí a pensar tan en grande como ellos, pero si a realizar los sueños, los anhelos. Recuerdo el día en que atentaron contra Ernesto Samper y la ciudad se paralizó; me había quedado sola en el teatro pues Fanny salió de gira y esa noche le pregunté si cerrábamos el teatro; “la función debe continuar..." la frase tan sonada, esa noche del año 89 la incorporé de por vida. Pienso que también tuve un diálogo con Fanny y allá, mi perspectiva filosófica, hizo germinar algunas cosas en esos teatros y en el festival.

Leer la proclama "Por un país al alcance de los niños", fue un momento determinante en mi vida; la obra y actividades de Gabriel García Márquez me marcaron mucho. Considero que mi trabajo ha tratado de estar cerca de sus perspectivas. En la Dirección de Artes del Ministerio de Cultura aprendí recorriendo país y encontrando a los gestores: James González, Reinaldo Melo, Adelaida Jaramillo, Wilder Guerra, tantos que desde sus oficios y funciones. Javier Gil, comunicador y filósofo, ha sido un referente para mí; me acompañó en la Dirección de Artes y era quien me apoyaba en quedarme en la zona intermedia, sin dejarme engullir por la administración, la polííca-policía y el lenguaje burocrático. De él bebo siempre agua fresca. 
Sus textos, su manera de cumplir con lo acordado, su manera de aproximarse al arte y a los artistas, fueron un faro.

Puedo decir igualmente que trabajar con Paula Marcela Zapata, me dio oportunidad de aterrizar algunos proyectos, una sensibilidad que llevaba en la piel. También me puso en debates, eso no siempre fue un idilio, pero estar en el Ministerio con esta mujer, si me marcó, me enseñó. Aprendo de Lucina Jiménez, compañera por muchos años y amiga mexicana con quien compartimos muchos objetivos comunes. Ella es una gestora cultura profesional muy rigurosa, un referente para muchos.

German Rey, Jesús Martín Barbero, Santiago Gómez-Castro, son referentes a los cuales siempre recurro. García Canclini, Ana María Ochoa, Georges Yudice; siempre releo algunos de sus textos para afirmar algún tema o actividad. Ahora últimamente, me ha interesado el movimiento de los Comunes en Barcelona. No comparto y no comprendo, mucho todos sus lineamientos, pero hay textos que aportan posibilidades.

Quiero mencionar a Marta Bustos, mi compañera, y a quien ya seguía desde antes de estar en la Secretaria de Cultura con ella, por uno de sus textos sobre el SINFAC muy esclarecedor y por su trabajo en la Alcaldía. Aprendí con ella, no solo sobre conceptos y modos de hacer, sino también actitudes que convienen al gestor cultural, como una distanciación. Y bueno, siempre están algunas lecturas filosóficas, o rasguños filosóficos, Sloterdijk, Rancierè, me han ayudado.

MBG: Cuando fue nombrada Secretaria de Cultura de Bogotá, El portal la Silla Vacía reseñó en su hoja de vida que usted "Conoce el sector de las artes y la cultura, y tiene experiencia previa en el sector público. Además, conoce los vericuetos de la administración de la cultura y, como escritora y representante de artistas, sabe cómo funciona ese mundo desde la orilla de los privados". ¿Cree usted que esta experiencia fue útil para el rol que asumió como Secretaria de Cultura en Bogotá, SCRD? CRC: Bueno, parte de las razones por las cuales acepté ese reto, es porque me sentía preparada para asumirlo. Siempre todo me cuesta mucho trabajo; todo es como la primera vez. Nunca había tenido una responsabilidad para el conjunto del sector cultural, el tema del patrimonio es muy exigente y ha evolucionado mucho, las prácticas artísticas cobijan una amplia gama de saberes y áreas de actividad e igual tuve que estudiar documentos antes de entrar. Pero sin duda, cuando llegó el momento de definirse, pensé que si podría enfrentar ese reto máximo; la experiencia y los conocimientos no son todo ante un cargo político, pero yo solo tenía ese recorrido para sustentarme, en eso se basó el alcalde Petro, que es una persona muy exigente pero también, intuitiva.

También la prensa se ha preguntado por mi coherencia política, pues venía de trabajar en el Ministerio de Cultura en el gobierno del presidente Uribe. Ya era seguidora de Gustavo Petro desde el Ministerio, no lo ocultaba pues había que salir corriendo a escuchar sus discursos en el senado. Yo pienso que finalmente el Ministerio no ha sido "el colorete" de ningún gobierno; no exigía militancias en los niveles técnicos, hay una estructura sólida que se gestó hace años y que le da esa relativa independencia. tal vez la pobreza también lo hace menos proclive a ser una presa interesante de la política tradicional.

MBG: ¿Cuál es su modelo de trabajo?, ¿podría definir/describir su modelo de gestión?, ¿qué elementos inciden con más importancia?

CRC: Paso mucho tiempo en la mesa discutiendo, recibiendo, en trabajo de mesa. Tal vez eso me viene de los años en el Festival y el teatro. Mucha acción en el día y al final, había que decantar y sentarse a escribir, a sistematizar. En la SCRD eso me iba desbordando de horarios, no creo que sea un buen modelo en extremos. Hay que modelar más.

En lo posible, busco ir al territorio, conocer la gente, las organizaciones, asistir a las producciones. La función pública es una instancia simbólica y a pesar de que haya distancia y poca capacidad de resolver los problemas individuales, las personas agradecen eso que llaman "Ia presencia". Ahora estoy extenuada.

Trabajo en cercanía con la Academia. Me es necesario la asesoría reposada y busco la academia o las academias en plural; en el Ministerio, a pesar de "pegarme la enredada", buscaba unir dos y tres universidades para que trabajaran juntas en un tema. Trabajo las relaciones internacionales, 
también por un gusto y visión de mis primeros años; me alejé mucho en la época de la Dirección de Artes, pues mi mundo era el país, pero con Paula volví a recobrar el interés de esas relaciones, que no son de ayuda y asistencia, son simplemente de intercambio y apoyo mutuo. Así tratamos de escoger nuestros aliados en la SCRD.

Tal vez se puede pensar que delego poco, pero no es desconfianza. Es el gusto por los temas y los procesos, me cuesta elegir y no estar en todo, pero cuando estoy, trato de estar como un par. Me costó llegar a la SCRD porque de todas maneras te hacen sentir un rango, que tienes la última palabra, que es como tú digas, yo manejo mal esas situaciones.

Me gusta trabajar con poetas, académicos, personas que conocen la comunidad, y con personas ordenadas y rigurosas, pues yo pienso que no lo soy. No me descuido en esto, pues para mi es la garantía de que yo pueda improvisar, experimentar un poco, dejar hablar a la experiencia, no estar tan en la norma. Entonces en los cargos públicos que he tenido, siempre he estado rodeada de abogados, economistas, administradores, estadistas; que son ejemplares en su trabajo y cuentan con una comprensión hacia la cierta especificidad que la cultura y el arte necesitan para ser trabajadas. Es cuestión de tener buenas parejas. No se trata de "sacarle la comba al palo", sino de ser también inventivos y aceptar que la complejidad también puede tener su eco en la administración. Ni la cultura es el único sector complejo. Así, hemos podido encontrar maneras de transformar la norma sin violentarla.

Trabajé con María Fernanda Cardoso, hacia el año 97. No logré traerla al FITB pero igual me hice empresaria de su Circo de Pulgas y en el año 98. Festival París Quartiers d'Eté la presentó en una carpa en la explanada del Centro de Arte Contemporáneo Georges Pompidou, fue un éxito. En este proceso me fue entregado un gran secreto, solamente lo develo aquí porque considero que es de gran ayuda para los jóvenes que cada día en mayor cantidad se sienten atraídos por la Gestión Cultural. La ciencia del domador de pulgas, como la de muchos artistas, creo yo, más que en "domar" a las pulgas, consiste en seguirlas. iMuy sencillo! En efecto para que suban el Monte
Everest, para que jalen una tractomula, caminen por la cuerda floja o bailen mambo, solo debes seguirlas. Pienso que la ciencia de un buen gestor cultural es contar con la imaginación, la osadía y la paciencia para "seguir" a artistas, cultores, comunidades en sus proyectos creativos. Es una capacidad de escucha, de apreciación y entrega creativas que están en la base de un gestor cultural. No voy a negar que el gestor creativo, no es un simple médium, el domador de pulgas, tampoco lo es, pero su rol se basa en la disposición hacia el otro, en la capacidad de acompañarlo y darle confianza, así se genera cultura, así se apoya la producción del acto creador. Así, en el Teatro Colón, no tuve reparos en decirle a mis colegas que ante un artista con un ego muy grande y fuera de sí, no tenía problema en convertirme en "tapete", siempre y cuando su propuesta artística lo ameritara. Así también, me planté ante los músicos de la Sinfónica que llegaban ebrios a los ensayos. La cultura es la vida, el arte, es una ruptura, un parto sin anestesia; somos producto de una inmensa felicidad y de un profundo dolor. El gestor debe tener sangre fría y amar tanto la creación como para andar en la cuerda floja de la vida. Muchas veces he considerado la gestión cultural como un acto de curaduría, una acción creativa. Pero, también, considero que hay justicia en la sublevación ante el poder de los curadores. La "expertica" individual, es siempre algo que debemos relativizar, es más definitivamente evitar.

Esta es una reflexión que me vuelve a la mente. Frente a la pregunta por el "modelo" o mis estrategias de gestión, necesitó enfatizar en la acción creativa, capaz de fantasía, de experimentación, de error, de avanzar al riesgo, aptitudes muy complejas de ejercer en la función pública o en el medio empresarial, pero más cercanas a la vida y a la posibilidad de transformación. Actitud creativa, no independiente, sino a través de la capacidad de generar comunión (participación) en torno a los procesos. Capaz de contagiar la comprensión y el gusto por los caminos de la creación que están lejos de ser autopistas. Me considero una gestora empírica, silvestre, gestada en medio de un bosque rico en cultura y arte. Ya otras generaciones llegan, más formadas y con herramientas conceptuales y técnicas más elaboradas. Pero a ellas, me dirijo, para darles el secreto del Circo de Pulgas. 
MBG: ¿Con cuáles referentes conceptuales o teóricos trabaja usualmente?

CRC: Uno, muy importante, o que me ronda siempre en la cabeza, pero no lo he sistematizado, es la idea de que la política cultural no existe. La cultura y el arte, siempre son políticos, cosa que es diferente, entonces al hablar de políticas culturales, lo que hago es política social cultural. Esto de la política cultural, me suena a manipulación, me hace ruido en la oreja, me parece que la intervención estatal en el campo cultural debe ser entendida, en primer lugar, como la gestión de un bien público y, en segundo lugar, como un rol de equidad y justicia social.

He trabajado durante ya casi tres décadas, detrás de la implementación de la educación artística y cultural, en todos sus niveles y modalidades. Esto como fundamento de la democracia cultural, concepto que es todavía difícil de apropiar y que cuando lo apropié, leyendo El Recurso de la Cultura, de Yudice, me acompaña como una sombra.

Otro referente conceptual es la idea de la mediación. Me parece que mi oficio en la gestión cultural es la de conservar un equilibrio precario, me he sentido como un funámbulo en la cuerda floja. De eso hablaba por allá en la introducción a un libro de los Salones Regionales, meterse con la cultura y con el arte, requiere asumir una distancia, que la puede dar una participación vigorosa, cuando existe, caso del movimiento animalista, por ejemplo. Cuando no, habría que convocarla, ir a por ella. Hay otros mecanismos de distanciación, el más importante es el de trabajar con lo que la gente quiere y no con lo que uno quiere o cree que la gente quiere, claro que lo que se da es un diálogo. Imposible silenciar lo que uno considera que es un buen camino, pero hay que temerle a quienes creen saber de cultura porque son cultos. El trabajo en grupo, en redes, la oreja en la academia, reconocer los canales de participación, son mecanismos que te acercan a la gestión cultural.

MBG: ¿Yo tuve la oportunidad de hacer parte de su equipo de trabajo en la SCRD y siempre me inquieto saber cómo conforma sus equipos, con quien le gusta trabajar?

CRC: Creo que lo he dicho ya en las respuestas anteriores. No tengo un "combo" pues en general mis compañeros, después de los trabajos que hemos hecho, que han tenido bastante estabilidad, van a otras fronteras o lugares. Trabajar con poetas, con filósofos pues además no soy una gran lectora; trabajar con personas prácticas que han estado cerca de la realidad de las comunidades, eso busco. También me gusta abrir oportunidades tanto a jóvenes como a adultos. Así que me he arriesgado a veces. Una anécdota importante es cuando aprendí en la ASAB a hacer afirmaciones positivas y buscar el equilibrio de género; allá aprendí que el campo cultural es fuertemente machista. A veces hay que buscarlo para los hombres. También he buscado afirmaciones territoriales, invitando gestores de la región al Ministerio.

MBG: ¿Cuáles cree han sido sus principales logros? CRC: Lograr mantenerme en el campo cultural en mi país por más de tres décadas. Los cuatro Festivales Iberoamericanos del inicio con Fanny. Yo no trabajé en el primero, me uní en el segundo. Contribuir a la curaduría y a desplegar las relaciones del Festival en el mundo; hacer sus eventos especiales. Haber luchado por traer algunas compañías y generar la Casa del Teatro, extensión de espíritu social de la Fundación, allá muchos directores tuvieron apoyo para hacer sus montajes; los talleres de perfeccionamiento especializados, eran de altísimo nivel. Hicimos un montaje con Anatoli Vassiliev.

Dirigir la ASAB. Fue corto, pero alcanzamos a revisar los programas, a comprar la sede y a invertir en una formación muy práctica que sacó a los estudiantes a los festivales, a talleres en contextos diferentes. La ASAB era un problema para el IDCT, yo la amaba. Con el apoyo de Camilo Noguera Calderón, padre de la Ley 30, se vio la imposibilidad de mantenerla bajo la tutela del IDCT, una lástima; esto es una discusión muy compleja que tiene que ver con las competencias del sector cultura en la educación artística y cultural.

En el Ministerio hice la tarea de adscribir el lote sobre la carrera once del Teatro Colón, el proyecto para su desarrollo, apoyé la decisión de que se iniciara una nueva restauración y participé en el grupo que entregó la primera licitación, esto siendo ya Directora de Artes. A la postre, esta se convertiría en el desarrollo del lote que se compró con la Asociación de Amigos, que volví a fundar en 2001 o 2002, creo. También abrí el Colón, de 80 funciones pasamos a 250, tratamos de hacerlo sentir en la región, trayendo los artistas a Bogotá. 
En el año 2000 junto con Gabriel García, gestor de la Localidad de Ciudad Bolívar del IDCT, iniciamos el proyecto Escuela de Artes y Nuevo Circo - Circo Ciudad, del Programa de Desarrollo Institucional y Comunitario. DIC-CB. Este proceso gestó la Fundación Circo Ciudad con los jóvenes de la primera cohorte de la escuela. Fui parte de ella hasta 2006 más o menos. La Unión Europea se retiró en el segundo año y el proyecto continuó hasta 2008. Muchos jóvenes de este proyecto viven actualmente de sus profesiones en Colombia y 5 países del mundo. Algunos han estudiado pregrado y avanzan hacia postgrados en su arte. CIRCO CIUDAD es un referente para los jóvenes en Ciudad Bolívar y en Bogotá en general.

En 2005 inicié las investigaciones y justificación del proyecto de la Ley que a la postre sería la Ley 1143 de 2011, Ley del Espectáculo Público. Convoqué a Julio Roberto Piza, exdirector de la DIAN y luego le siguieron otros asesores como Miguel Urrutia, exministro de Hacienda y director del Banco de la República. Gracias a la comprensión y apoyo de la abogada Adriana Hurtado, entró al grupo líder con Fernando Zarama, quien sería un pilar para sacar adelante esta Ley. Convocamos otros distritos y a los artistas y gestores de las artes escénicas. Durante 6 años, logramos no cejar en este propósito. La Ley se radicó en 2009 , pero la alianza con Simón Gaviria se truncó por la división del liberalismo con el Uribismo. La ley fue demostrando su pertinencia a pesar de su complejidad y fue ganando adeptos. Considero este uno de los proyectos más importantes que he impulsado. Fue la Ministra Mariana Garcés con el apoyo de gestores y artistas que comprendían la Ley, la que un año después de estar en el gobierno logró sacarla adelante.

Tuve a mi cargo la puesta en marcha y ejecución del Plan Nacional de Música para la Convivencia, durante 6 años. Hoy, el plan continua vigente. Construimos el Plan Nacional de las Artes entre 2004-2005. En 2007 el Plan Nacional de Danza y en 2009 el Plan Nacional de Teatro. Se llamaban Planes pues la administración Moreno, no reconoció el Plan Nacional para las Artes, que guío y estructuró el subsector durante un tiempo.

Diseñamos e implementamos el programa Colombia Creativa, profesionalización de artistas que inició con 7 universidades del país y una cobertura de 900 artistas del teatro, la música y la danza. Éste programa ha tenido continuidad y su cobertura alcanza los 1.500 artistas de muchas regiones del país. Propuse y lideré la documentación para la inclusión en la lista representativa del Patrimonio Inmaterial de la Humanidad a la música de marimba, los cantos y bailes tradicionales, esto ocurrió entre 2008 y 2009. En 2015, la Unesco amplió esta declaratoria para integrar a la zona de esmeraldas en el Ecuador a este mismo territorio cultural. Actuación especial tuvieron los profesores Jorge Franco y Claudia Cruz.

Se alcanzaron a tener cerca de 64 talleres de escritura creativa adscritos a la Red Relata. Especial mención hago del taller Libertad bajo palabra del escritor y poeta Zuleta. Los resultados de este taller eran publicados por NORMA y continúan en la actualidad. Dos salones Nacionales de Artistas $y$ tres Salones regionales, el presupuesto de la Dirección de Artes llegó a ser similar al de la Dirección de Patrimonio, sin contar los recursos de IVA de la telefonía celular.

En la SCRD, diseñamos e implementamos la política de integración de las artes y el deporte en la educación para la primera infancia y la básica en la administración de Bogotá Humana. En un esfuerzo sin precedentes, con un equipo de profesionales que había soñado y trabajado fomentando la educación artística durante muchos años y con la clara voluntad del alcalde Petro, se iniciaron actividades en 2013 que relacionaban a artistas y deportistas de la ciudad con el sistema educativo. Más de 150 mil niños y niñas contaban con dos o más horas de deporte y artes a la semana. Se crearon y pusieron en marcha los CLANES, centros Locales de Artes para la niñez y la juventud. Esta política cuenta con un Acuerdo del Consejo de Bogotá que fue votado por unanimidad.

Durante la pasada administración no hubo muerte de animales en la Plaza de Santamaría. Este hecho constituye sin duda un precedente significativo para una corriente social y cultural muy importante en nuestra época. Esto se logró porque los agentes de la tauromaquia tenían problemas legales y porque actuamos con tranquilidad y escuchando las necesidades de este medio. Así del problema legal, se pasó a solicitar la aclaración de la Corte Constitucional y de ahí a la restauración del 
inmueble que tenía 83 años sin que se le hubiera hecho ningún trabajo de adecuación a las normas.

La Red de Bibliotecas Públicas de Bogotá, paso a ser parte del sector Cultura. Competencias también en el orden del patrimonio también se lograron trasladar de Planeación Distrital al sector Cultura. El Sector conformado por el subsector del deporte y el de cultura, contó con un plan sectorial e indicadores basado en un estudio del Plan Decenal levantado por la anterior administración. Apoyamos la Agenda 21 y la redacción de su documento Acciones y Bogotá entró a hacer parte de la Red de Ciudades Creativas de la Unesco. También habría que pensar en lo que no logré, que vieran la luz las políticas culturales 2016-2021 para Bogotá. La FUGA como Instituto de las culturas o de la diversidad, como quería Petro. La política de Casas de la Cultura. Los planes anuales de cultura obligatorios.

MBG: Usted ha trabajado para varios gobiernos. ¿Cuáles cree que han sido los hilos conductores de su gestión?

CRC: Considerar siempre que mi trabajo tiene un impacto social y político y no solamente estético. Buscar construir proyectos con un impacto social sea para los agentes del sector o para la población en general con respecto a la cultura y las artes.

Luchar por la valoración de las artes y la cultura, entre los dirigentes políticos, los otros sectores de la política pública.

Buscar generar debate y pensamiento en torno a lo que se hace, sin dejar de hacer.

Entender que sin Educación no hay cultura y que la educación sin cultura, es seca, o imposible. Tratar de acercar esos dos mundos a pesar de la importancia de su distinción. Son como pariente rico y pariente pobre, diría García Márquez.

Tratar de trabajar para la descentralización y la participación, no ha sido fácil, no he sido tan disciplinada y persistente en este frente. Estoy convencida de que son líneas fundamentales de la política cultural.

Buscar integrar competencias que están por allá refundidas en otros sectores y que son de Cultura y entender cómo se podría manejar la "transversalidad" de la cultura. Identificar lo cultural y el trabajo que hay que hacer en otras áreas y en la vida de las personas, sin sectorizarla.

MBG: ¿Cuáles son los principales retos, según su experiencia, en la gestión del campo cultural en la ciudad?

CRC: En la ciudad, articular el adefesio que se montó por cuenta de la separación de la "cabeza del sector" con sus entidades adscritas. Esto para una institucionalidad tan pequeña y pobre, no se justifica. Desde el punto de vista programático lograr un sector con indicadores compartidos y conseguir que esos indicadores (e índices) sean apropiados por las diferentes administraciones. Trabajar por la descentralización de la gestión cultural abriendo el cargo del responsable de cultura; esta descentralización es imposible sin una voluntad de cambio desde el ordenamiento político de la ciudad.

Mantener y fortalecer los programas de concertación cultural en zonas vulnerables. Mayor desarrollo de la institucionalidad y de la inversión acorde con las transformaciones culturales: las prácticas culturales (practicas: artesanías, lenguas, gastronomía; asuntos poblacionales). La comunicación y los medios solo están en Canal Capital que no es manejado con gran autonomía. Ingreso del diseño, la arquitectura y las artes electrónicas a las áreas atendidas, desarrollar la red de centros virtuales. Inversión en infraestructura cultural permanente. Revisar territorialización de la oferta cultural gratuita y desarrollar la política de Industrias Creativas en articulación con la Cámara de Comercio Articular la ciudad con Cundinamarca, Boyacá y el Tolima. 